\title{
Teknologi Bluetooth dengan Mekanisme Multihop
}

\author{
Endar Nirmala \\ Teknik Informatika, Universitas Pamulang \\ Jalan Surya Kencana No. 1, Tangerang Selatan \\ e-mail: endarnirmala@gmail.com
}

\begin{abstract}
Abstrak
Bluetooth is a wireless communication technology that is used to exchange information, at a lower cost, use low power, the ability to work or interact between applications through approved protocols is very good, and easy operation. The Bluetooth operating range works on the $2.4 \mathrm{GHz}$ unlicensed ISM (Industrial, Scientific and Medical) frequency band using a frequency hopping tranceiver that is able to provide real-time data and voice communication services between Bluetooth hosts. When Bluetooth devices communicate with each other, they will form a dynamic network called piconet, a network consisting of master and slave, in one piconet of no more than 7 slaves. Bluetooth also supports connections between piconets called scattemets. The mechanism for connecting between one piconet and another is called a hop mechanism.
\end{abstract}

Keywords: master, slave, piconet, scatternet, hoping

\section{Pendahuluan}

Teknologi Bluetooth dirancang untuk menghubungkan antara peralatan di sekitamya tanpa menggunakan kabel. Salah satu produk bluetooth diantaranya berupa kartu PC atau adapter USB yang dimasukkan ke dalam suatu perangkat. Perangkat atau device yang dapat diintegerasikan dengan teknologi bluetooth diantaranya mobile phone, Laptop, PDA (Personal Digital Assistant), router, headset, printer, kamera dan sebagainya. Aplikasi-aplikasi yang disediakan pada layanan bluetooth antara lain: transfer file $P C$ to PC, PC to mobile phone, PC to Personal Digital Assistant, wireless headset, dan menghubungkan jaringan wilayah local melalui ethemet access point.

\section{Teknologi Bluetooth}

Perangkat Bluetooth pada umumnya dapat saling berhubungan dan berkomunikasi dengan area diantara 1 sampai $100 \mathrm{~m}$. Jarak masksimal diperoleh berdasarkan daya keluaran yang digunakan dalam modul Bluetooth. Modul Bluetoooth dalam hal ini merupakan chip Integreted circuit khusus komunikasi yang telah mmenggunakan aturan atau standar yang mengatur atau mengijinkan terjadinya hubungan, komunikasi, dan perpindahan data dalam Bluetooth. Berdasarkan daya output dan jarak jangkauannya terdapat tiga kelas Bluetooth, yaitu daya kelas 1 yang beroperasi pada data antara 100 $\mathrm{mW}(20 \mathrm{dBm})$ hingga $1 \mathrm{~mW}(0 \mathrm{dBm})$, dan dirancang untuk peralatan Bluetooth dengan jarak jangkauan hingga $100 \mathrm{~m}$. Daya kelas 2 beroperasi antara $2.5 \mathrm{~mW}(4 \mathrm{dBM})$ dan $0.25 \mathrm{~mW}(-6 \mathrm{dBm})$, dan dirancang untuk jarak jangkauan sampai 10 $\mathrm{m}$. Daya kelas 3 memiliki daya maksimal hingga $1 \mathrm{~mW}(0 \mathrm{dBm})$ dan bekerja untuk peralatan atau perangkat dengan jarak sekitar $1 \mathrm{~m}$.

\section{Arsitektur Bluetooth}

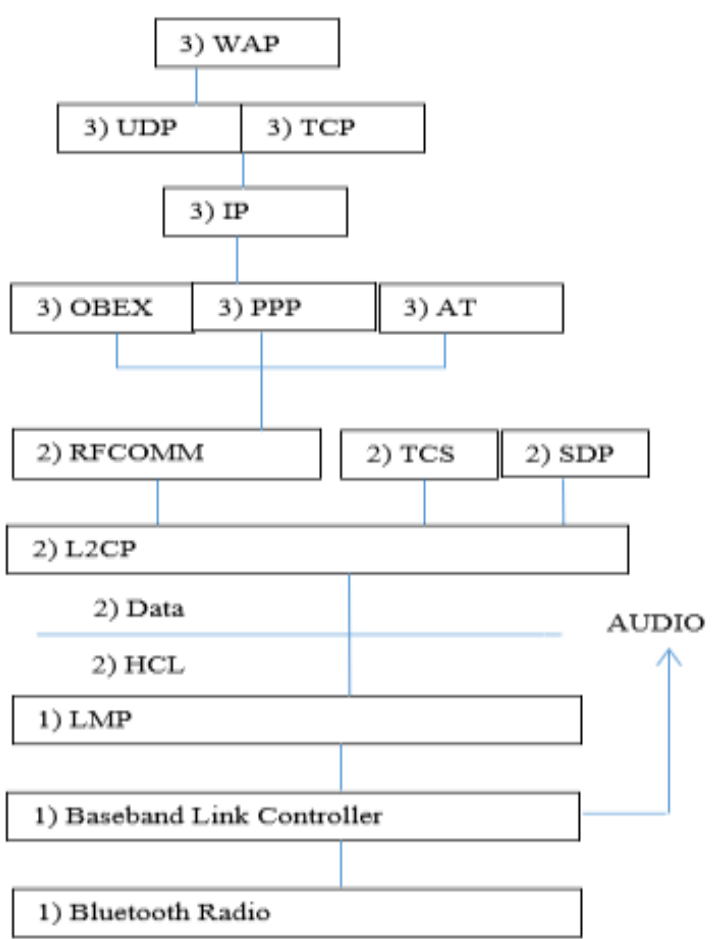

Gambar 1.1 Bluetooth Protocol Stack 


\section{Service Discovery Protocol (SDP)}

Layer ini berguna untuk melakukan pencarian layanan pada peralatan Bluetooth lain

\section{Radio Frequency Communication (RFCOMM)}

Layer ini berfungsi sebagai antarmuka serial, seperti halnya RS-232.

\section{Object Exchange (OBEX)}

Layer ini berfungsi menyediakan fasilitas transfer obyek atau file.

\section{Telephony Control Service (TCS)}

Layer ini berfungsi menyediakan fasilitas transfer obyek atau file

\section{Point to Point Protocol (PPP), IP, TCP, UDP dan WAP}

Layer ini digunakan untuk keperluan koneksi ke Internet

\section{AT Command}

Layer ini digunakan untuk mengontrol telepon atau modem

Secara umum, sebuah perangkat Bluetooth meliputi sebuah unit radio, sebuah unit link controller, dan sebuah unit support, yang berfungsi untuk proses manajemen sambungan. Link Controller berhubungan dengan pengaturan proses transfer dari modul Bluetooth termasuk diantara segala sesuatu yang berkenaan dengan Audio, Coding dan Enkripsi. Link manager bertugas dalam proses pencarian peralatan Bluetooth lain serta bagaimana berkomunikasi dengan modul link manager didalamnya. Selain itu tersedia sebuah Host Controller Interface (HCI) yang merupakan antarmuka bagi peralatan dimana modul Bluetooth tersebut berada, fungsinya untuk mengakses fung-fungsi yang dimiliki oleh modul Bluetooth tersebut. Semua perintah ke dan dari modul Bluetooth akan melewati HCI tersebut.

\subsection{Mode Operasi Bluetooth}

Peralatan atau perangkat Bluetooth dapat beroperasi dalam beberapa mode. Sebelum terjadi koneksi, semua peralatan berada pada mode stanby, yang akan selalu siaga setiap 1,28 detik untuk memperoleh pesan inquiry atau page. Bluetooth ketika menghubungkan perangkat yang dituju menggunakan mode page, dimana mode inquiry akan sangat dibutuhkan jika alamat tujuan tidak terdeteksi.
Pada saat proses paging berlangsung peralatan atau perangkat yang terhubung harus mengetahui alamat dan system clock perangkat atau peralatan tujuan untuk menentukan akses paket data. Informasi alamat dan system clock ini disediakan pada proses pencarian atau inquiring.

Beberapa mode operasi tersediat ketika peralatan-peralatan terkoneksi, yaitu active, sniff, hold, dan park. Peralatan atau perangkat secara aktif berpartisipasi dalam kanal komunikasi (transmisi data) pada mode active. Aktivitas (duty cycle) peralatan berkurang ketika transmisi data hanya dapat terjadi pada time slot tertentu, pada mode sniff.

Pada mode sniff aktivitas peralatan lebih tinggi dibanding pada mode hold, di samping itu peralatan atau perangkat dapat melakukan kegiatan lain seperti paging dan inquiring pada mode hold. Sedangkan pada mode park, peralatan tidak berpartisipasi dalam piconet, tetapi tetap mempertahankan sinkronisasi dengan kanal komunikasi.

\section{Profiles Bluetooth}

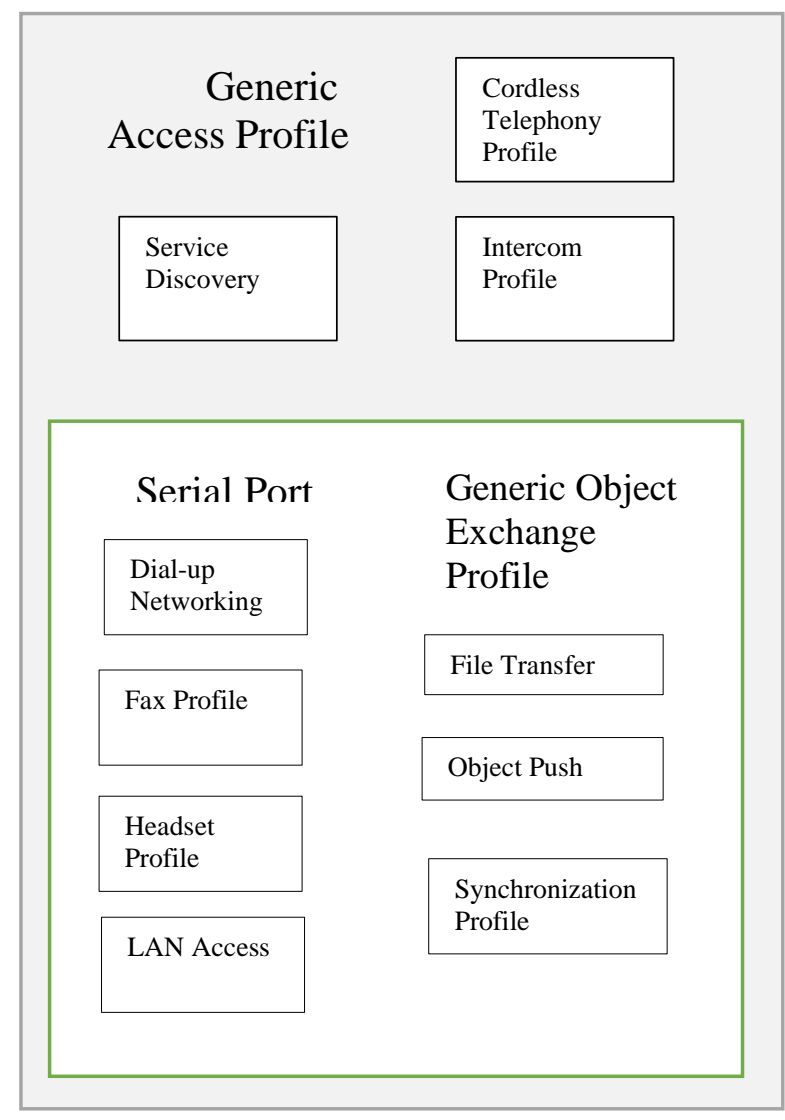

Gambar 2.1 Profiles Bluetooth 


\section{Generic Access Profile (GAP)}

GAP menggambarkan prosedur peralatan Bluetooth ketika mereka ingin menghubungkan, menemukan identitas, dan menyediakan layanan security.

\section{Serial Port Profiles (SAP)}

SAP menyediakan kabel emulation RS 232 yang merupakan standar GSM untuk menghubungkan peralatan komputer, PDA dan Ponsel

\section{Service Discovery Aplication Profile(SDAP)}

Profil ini menggambarkan fitur dan prosedur yang digunakan untuk menemukan layanan pada peralatan Bluetooth lain dan memberi informasi layanan apa saja yang disediakan.

\section{Generic Access Profile (GAP)}

Profil ini merupakan basis bagi semua profile di dalam system Bluetooth dan mendefinisikan fungsionalitas dasar, seperti prosedur koneksi, device dicovery, link management, dan prosedur security.

\section{Service Discovery Application (SDA)}

Profile ini mendefinisikan fitur dan prosedur bagi aplikasi di peralatan Bluetooth untuk menemukan layanan yang terdaftar di peralatan lain dan mendapatkan informasi yang berhubungan dengan layanan tersebut.

\section{Cordless Telephony Profile}

Profile ini memungkinkan peralatan Bluetooth berperan sebagai telepon seluler untuk berkomunikasi dengan PSTN melalui titik akses Bluetooth

\section{Intercom Profile}

Profile ini menangani komunikasi suara dua arah diantara peralatan-peralatan Bluetooth

\section{Serial Port Profile}

Profile ini memungkinkan peralatan Bluetooth mengemulasi port-port serial PC menggunakan protocol RFCOMM

\section{Fax Profile}

Profile ini mendefinisikan fungsionalitas untuk menggunakan peralatan Bluetooth dial-up networking gateway

\section{Dial-up Networking Profile}

Profile ini mendefinisikan fungsionalitas untuk menggunakan peralatan Bluetooth dial-up networking gateway

\section{Headset Profile}

Profile ini mendefinisikan fungsionalitas yang diperlukan untuk melakukan transfer audio, misalnya dengan headset Bluetooth nirkabel

\section{LAN Access Profile}

Profile ini mendefiniskan fungsionalitas untuk menggunakan peralatan Bluetooth sebagai LAN Access Point

\section{Generic Object Exchange Profile}

Profile ini menyediakan dukungan bagi protokol OBEX melalui media Bluetooth

\section{Object Push Profile}

Profile ini mendefinisikan fungsionalitas untuk mengatur pertukaran obyek dalam format vCard atau $v$ Calender berdasarkan GOEP

\section{Aspek Keamanan}

Keamanan merupakan aspek yang penting ketika berkomunikasi tanpa kabel. Oleh karena itu, mode keamanan didefinisikan di dala spesifikasi Bluetooth berdasarkan 3 komponen utama, yaitu otentitikasi, enkripsi dan otorisasi.

Mode keamanan merupakan bagian GAP. Perlatan Bluetooth yang berkualitas harus mengimplementasikan GAP sehingga memiliki implementasi mode keamanan. GAP mendefinsikan 3 mode keamanan, yaitu :

a. Mode keamanan 1: no security

b. Mode keamanan 2 : service level enforced security

c. Mode keamanan 3 : link level enforced security

\section{Protocol Bluetooth}

\subsection{Protocol OBEX}

Obex adalah salah satu jenis protocol yang digunakan dalam pertukaran obyek dan data. Pada awalnya protocol ini didesain untuk digunakan pada fitur infra merah. Akan tetapi dalam perkembangan selanjutnya protocol ini juga diimplementasikan pada Bluetooth, RS232, USB dan WAP.

OBEX merupakan protocol yang berbasis sesi yang memungkinkan berbagai request/response diperlukan dalam sebuah sesi saja. Sebuah sesi OBEX diinisialisasi dengan sebuah OBEX CONNECT request dan diselenggarakan setelah perlatan lain menerimannya dan mengirimkan respon sukses. Peralatan yang menginisialisasi koneksi OBEX 
client, sedangkan peralatan satunya lagi dinamakan OBEX Server.

Ketika sebuah sesi telah dibuat, data selanjutnya ditransfer menggunakan PUT request. Peralatan lain yang berada jauh menjawab data dengan cara mengirimkan sebuah respon dengan sebuah status code.

\subsection{OBEX Over Bluetooth}

Dalam perlatan Bluetooth, sebuah SyncML client harus dapat bertindak baik sebagai OBEX client maupun sebagai OBEX Server, atau keduanya. SyncML server juga harus dapat berfungsi sebagai OBEX Server dan Client. Gambar 4.2 memperlihatkan protocol stack yang ada ketika SyncMl dan OBEX bekerja pada peralatan Bluetooth.

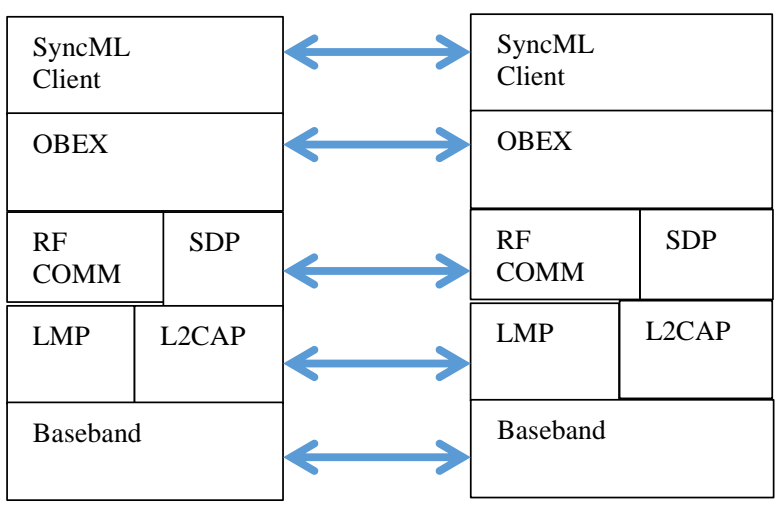

Gambar 4.2 OBEX over Bluetooth

Baseband LMP dan L2CAP merupakan lapisan OSI tingkat 1 dan 2 pada protokol Bluetooth. RFCOMM merupakan adaptasi dari Bluetooth terhadap standar GSM TS 07.10. SDP adalah singkatan dari Bluetooth Service Discovery Protocol.

Lapisan SyncML Client pada gambar 4.2 merupakan entitas yang menyediakan fungsionalitas sync client sebagai agen. SyncMl Server merupakan software yang menyediakan fungskonlitas sebagai mesin sinkronsisasi. SyncML client dapat bekerja sebagai OBEX Client maupun sebagai OBEX Server di lapisan protokol OBEX. Sebagai konskuensinya, SyncML server dapat bekerja baik sebagai sebuah OBEX client maupun sebagai OBEX Server. Aturan dari OBEX tergantung dari kondisi mana diantara SyncML client atau SyncML server yang menginisialisasi sinkronisasi.

\section{Sistem Hop}

Pada teknologi tanpa kabel Bluetooth dapat dimungkinkan komunikasi terhubung antar dua titik (peer to peer) dalam jarak pendek. Teknik fast frequency-hoping spread spectrum (FHSS) adalah teknik konunikasi yang digunakan antar perangkat Bluetooth. Interferensi dapat dicegah oleh FHSS dengan mengubah frekuensi transmisi smenjadi 1600 kali per detik dan seandainya terjadi interferensi dalam satu frekuensi maka hanya transmisi yang dilakukan pada frekuensi itu saja yang terpengaruhi. Selain itu FHSS dapat memberikan sistem keamanan pengiriman data antara perangkat yang terhubung sehingga perangkat akan lebih sulit untuk disadap. Rendahnya kemapuan transmisi yang dipancarkan akan mencegah terjadinya transmisi yang dipancarkan terpropogasi jauh dan membuat hubungan antar transmisi lebih sulit diputus.

\subsection{Cara Kerja}

Di beberapa negara, sebagai contoh Perancis banyaknya lompatan dalam sistem berjumlah 23, sementara negara Amerika Utara pita gelombang dari standar Industrial Scitentic, and Medical (ISM) terbagi menjadi 79 lompatan kanal dengan kapasitas pengiriman 1 watt per saluran. Sinyal perlu ditransmisi pada pita frekuensi yang lebih besar dari bandwidth yang digunakan pada sinyal informasi, sehingga distribusi spektrum harus dibuat.

Dalam proses penyebaran energi yang dikirim oleh pemancar biasanya akan terpusat pada pita frekuensi disebut sebagai pita sempit (narrow band), yang dapat melewati beberapa saluran pita frekuensi dalam spektrum elektromagnetik yang lebih besar. Keuntungan adalah meningkatkan kapasitas sinyal dan mengurangi tingkat inferensi narrowband.

Pada teknik modulasi yang dikenal dalam proses transmisi sinyal menggunakan teknik dispersi spektrum, salah satunya adalah frequency hopping. Pada proses ini frekuensi yang berbedabeda akan dikirim oleh setiap paket. Hop rate merupakan istileh kecepatan perpindahan antar paket tersebut. Kecepatan tinggi rata-rata lompatan berkisar 1600 hop/detik, dengan tujuan memperoleh paket yang pendek serta mencegah interferensi. Teknik ini menggunakan proses switching yang berulang atau perpindahan dari frekuensi-frekuensi selama transmisi radio.

Untuk mengurangi efektivitas "perang elektronik" yang terjadi karena gangguan dalam sistem telekomunikasi atau intersepsi ilegal maka proses ini sering dilakukan. Proses ini sering 
disebut sebagai akses ganda dengan pembagian kode hop frekuensi atau FH-CDMA.

\subsection{Mekanisme HOP}

Suatu perlengkapan Bluetooth dapat timeshare antar piconet yang berbeda. Khususnya suatu perlengkapan dapat mencari master dalam satu piconet dan menjadi slave pada piconet lain, atau bisa menajadi slave dalam berbagai piconet. Perlengkapan dengan multi-peran akan bertindak sebagai pintu gerbang ke piconet terdekat, dengan demikian akan menghasilkan jaringan multihop yang desebut dengan scatternet.

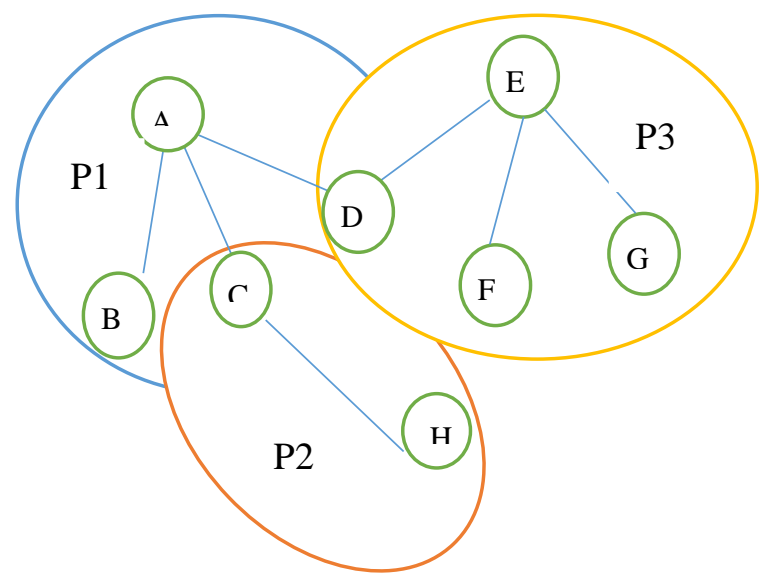

Gambar 5.2 Contoh Topologi Bluetooth

Gambar 5.2 merupakan contoh dari suatu scatternet yang terdiri dari tiga piconet yang terpisah. P1, P2 dan P3. Masing-masing piconet dikendalikan dengan master yang terpisah (perlengkapan A, C dan E) dengan terdiri dari satu atau lebih slave. Perlengkapan C, yang menghubungkan P1 dan P2, adalah sebagai slave di piconet P1 dan sebagai master pada piconet P2 .

\subsection{Skenario Implementasi}

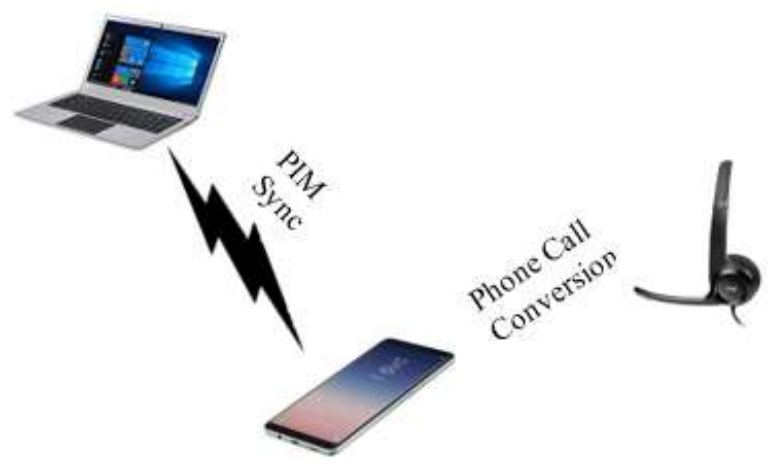

Gambar 5.3 Contoh penggunaan Scatternet
Sebagai contoh dalam kasus ini user ingin menyamakan penanggalan antara telpon selular dan laptop, sementara pada waktu yang sama telpon selular juga melakukan percakapan dengan menggunakan headset Bluetooth. Pada skenario ini ponsel bertindak sebagai master (kearah headset) dan sebagai slave (kearah laptop). Dalam implementasinya scatternet lebih membutuhkan keefektifan sehingga mengabaikan kecepatan data.

Pada kasus diatas terdapat situasi yang cukup kompleks dimana dua aplikasi membutuhkan logical links yang berbeda dan bekerja pada waktu yang sama, satu pihak melibatkan transmisi data dan dilain pihak melibatkan transmisi suara.

Adapun logical links yang digunakan dalam kasus ini adalah SCO-links dimana telpon selular berperan sebagai master untuk headset dan ACLlinks dimana ponsel berperan sebagai slave untuk laptop.

Tipe koneksi ada dua macam yaitu ACL dan SCO. ACL merupakan tipe koneksi packetswitched yang digunakan untuk transmisi data, baik simetris maupun asimetris. Sedangkan SCO merupakan tipe koneksi circuit switched yang digunakan untuk transmisi suara simetris.

Entitas dalam suatu paket data adalah access code (72 bit), header (54 bit) dan payload (0-27 45 bit). ACL membutuhkan ketiga entitas di dalam mengirim data.

Terdapat 3 metoda yang digunakan Bluetooth untuk memastikan data yang ditransmisi benar, yaitu:

a. Forward Error Correction (FEC), digunakan di header dengan menambahkan check bit dan dapat pula digunakan di playload;

b. Automatic Repeat Reques (ARQ), merupakan metoda di mana playload akan ditransmisi ulang secara otomatis bila penerima tidak mengirim pemberitahuan (Acknowledgement) dimana pemberitahuan ini disertakan pada header paket kembalian

c. Cyclic Redundancy Check (CRC), merupakan metoda yang digunakan untuk memeriksa apakah isi playload benar.

ACL memiliki 2 tipe paket data, yaitu DataHigh-Rate (DH) dan Data-Medium Rate (DM) dengan 3 pilihan: 1 slot, 3 slot, atau 5 slot.

\section{Kesimpulan}

Dengan mekanisme multihop, performance teknologi Bluetooth memiliki potensi yang besar 
untuk mencapai jangkauan yang lebih luas, bahkan lebih jauh lagi dengan memodifikasi pada peralatan Buetooth tidak menutup kemungkinan Bluetooth akan menyamai kedudukan WAN.

\section{Daftar Pustaka}

Specification of the Bluetooth System Version 1.1, http://www.bluetooth.com

Mahmoud, Q.H. Part II: Java APIs for Bluetooth Wireless Technology, http://www.java.sun.com

Haartsen, J., Bluetooth: Vision, Goals, and Architecture, Mobile Computing and Communication Review, volume 1, number 2.

Singh A., Demand Surges for Bluetooth Apps, http://www.expresscomputeronline.com

Ramiro Liscano, Introduction to Bluetooth Networking, 